\title{
Unexplained Gastrointestinal Symptoms After Abuse in a Prospective Study of Children at Risk for Abuse and Neglect
}

\author{
Miranda A. L. van Tilburg, PbD \\ Desmond K. Runyan, MD, DrPH \\ Adam J. Zolotor, MD, MPH \\ J. Christopher Grabam, PbD \\ Howard Dubowitz, MD, MS \\ Alan J. Litrownik, $\mathrm{PbD}$ \\ Emalee Flaberty, MD \\ Denesh K. Chitkara, MD \\ William E. Whitebead, PbD
}

\begin{abstract}
PURPOSE Unexplained gastrointestinal symptoms are more common in adults who recall abuse as a child; however, data available on children are limited. The aim of this study was to investigate the association of childhood maltreatment and early development of gastrointestinal symptoms and whether this relation was mediated by psychological distress.
\end{abstract}

METHODS Data were obtained from the Longitudinal Studies of Child Abuse and Neglect, a consortium of 5 prospective studies of child maltreatment. The 845 children who were observed from the age of 4 through 12 years were the subjects of this study. Every 2 years information on gastrointestinal symptoms was obtained from parents, and maltreatment allegations were obtained from Child Protective Services (CPS). At the age of 12 years children reported gastrointestinal symptoms, life-time maltreatment, and psychological distress. Data were analyzed by logistic regression.

RESULTS Lifetime CPS allegations of sexual abuse were associated with abdominal pain at age 12 years (odds ratio $[\mathrm{OR}]=1.75 ; 95 \%$ confidence interval $[\mathrm{Cl}]=1.1-2.47)$. Sexual abuse preceded or coincided with abdominal pain in $91 \%$ of cases. Youth recall of ever having been psychologically, physically, or sexually abused was significantly associated with both abdominal pain and nausea/vomiting (range, $\mathrm{OR}=1.5$ [95\% Cl, 1.1-2.0] to 2.1 [95\% Cl, 1.5-2.9]). When adjusting for psychological distress, most effects became insignificant except for the relation between physical abuse and nausea/vomiting (OR $=1.5 ; 95 \% \mathrm{Cl}, 1.1-2.2)$.

CONCLUSION Youth who have been maltreated are at increased risk for unexplained gastrointestinal symptoms, and this relation is partially mediated by psychological distress. These findings are relevant to the clinical care for children who complain of unexplained gastrointestinal symptoms.

Ann Fam Med 2010;8:134-140. doi:10.1370/afm.1053.

\section{INTRODUCTION}

T $\mathrm{n}$ the United States 48 in 1,000 children are reported for possible maltreatment (abuse and neglect) to Child Protective Services (CPS) each

year. ${ }^{1}$ Maltreatment is confirmed in one-quarter of these cases after investigation. ${ }^{1}$ This number likely constitutes only a small proportion of all maltreatment, because for every child that CPS identifies as abused or neglected, 3 to 40 cases go unreported. ${ }^{2-4}$ Childhood maltreatment has negative sequelae in terms of both psychological and physiologic health. ${ }^{5}$ By early adulthood about one-third of child maltreatment victims suffer from depression, ${ }^{6}$ and more than $20 \%$ suffer from posttraumatic stress disorder. ${ }^{7}$ The risk for attempted suicide and poor health is almost twice as high as in individuals who have not been maltreated. ${ }^{6,8}$

One of the more extensively studied long-term health outcomes of child abuse is gastrointestinal symptoms in adulthood. Adult survivors of abuse 
are twice as likely to suffer from disabling and chronic gastrointestinal symptoms as adults who have not been abused. ${ }^{9-15}$ One-half to two-thirds of patients in a tertiary care gastroenterology clinic reported a history of abuse. ${ }^{16-18}$ Sexually abused women, in particular, report a high incidence of unexplained gastrointestinal problems. ${ }^{15,19}$ In addition to abuse, neglect has been associated with increased physical symptoms among adults with abdominal pain. ${ }^{20-23}$ In light of these relationships, some experts have recommended that physicians ask about physical or sexual abuse when a patient complains of unexplained gastrointestinal symptoms. ${ }^{24,25}$

Despite a growing awareness of the relationship between child abuse and neglect and gastrointestinal symptoms later in life, only 1 study has focused on the impact of abuse on gastrointestinal symptoms in children. A chart review study found that $26.4 \%$ of children who were medically evaluated after sexual abuse complained of unexplained abdominal pain in the 1 to 2 years after their visit compared with only $6.9 \%$ of children who were not abused. ${ }^{19}$ There is a need to study children who have suffered other types of maltreatment, such as physical abuse and neglect.

Maltreatment could affect gastrointestinal symptoms through several mechanisms, including increased emotional distress and the effects of injury on hypersensitivity of the visceral nervous system, ${ }^{26-28}$ although the latter is less likely, given that few children have physical injuries resulting from abuse. ${ }^{1}$ Since distress is associated both with maltreatment ${ }^{5}$ and reporting of gastrointestinal symptoms, ${ }^{29}$ it may mediate the relationship between them. Furthermore, both maltreatment and psychological distress are associated with increases in somatization (a tendency to experience and report unexplained somatic symptoms and to misattribute them to disease). ${ }^{30-32}$

The aim of this study was to investigate the association between maltreatment and unexplained gastrointestinal symptoms in youth. We hypothesized that a history of abuse or neglect (determined by CPS records and self-report) increases the risk for self- and parent-reported unexplained gastrointestinal symptoms in youth, and that psychosocial distress would partly mediate this relationship.

\section{METHODS}

\section{Subjects}

Data were drawn from the 1,354 children enrolled in the Longitudinal Studies of Child Abuse and Neglect (LONGSCAN) (described in the Supplemental

\footnotetext{
Appendix 1, available online at http://annfammed. i org/cgi/content/full/8/2/134/DC1). LONGSCAN is a multisite, longitudinal study examining the
}

antecedents and consequences of child maltreatment. Children studied were chosen so that they varied by levels of exposure to maltreatment or risk of maltreatment. Overall, the cohort had a high prevalence of abuse or neglect. At the time of data extraction, 954 youth had completed interviews at age 12 years, and data on gastrointestinal symptoms were available for 845. Youth who had missing data on gastrointestinal symptoms did not differ by sex, race, or CPS-recorded and self-reported maltreatment from the children who were included.

\section{Measures}

\section{Gastrointestinal Symptoms}

Data on gastrointestinal symptoms were derived from the Child Behavior Check List (CBCL) completed by caregivers at ages $4,6,8$, and 12 years, and from the companion Youth Self-Report (YSR) completed by the children at age 12 years. ${ }^{33}$ The CBCL and YSR assess a child's potential behavioral problems. Item 56 of the CBCL and YSR asks caregivers and youth, respectively, to identify physical problems without a known medical cause in the past 6 months and includes abdominal pain or cramps, nausea/feeling sick, and vomiting/throwing up. We combined the latter 2 symptoms into 1 category (nausea/vomiting) because of the low frequency for both nausea and vomiting and their frequent co-occurrence.

Discrepancies between youth and caregiver reports of gastrointestinal symptoms are to be expected, because parent-child concordance for unexplained gastrointestinal symptoms is usually fair to low. ${ }^{34,35}$ In the current study children reported 2 to 3 times more gastrointestinal symptoms than did their parents. Thus, we considered a child to be having a symptom if either the caregiver or the child reported the symptom.

\section{Psychological Distress}

The YSR, which was completed by youth aged 12 years, assesses emotional and behavioral problems. ${ }^{33}$ The YSR, a widely used instrument with excellent psychometric properties, includes 8 problems scales. We used the anxious/depressed problem scale to assess psychological distress.

\section{Maltreatment}

CPS maltreatment narratives were coded using the Modified Maltreatment Classification System (MMCS). ${ }^{36}$ The MMCS has codes for 5 different types of maltreatment: (1) emotional maltreatment; (2) lack of supervision; $_{i}$ (3) failure to provide food, hygiene, clothing, shelter, or medical care ${ }_{i}(4)$ sexual abuse $_{i}$ and (5) physical abuse. Youth were identified as being exposed or not exposed to each of these 5 types and coded as 
maltreated if there was at least 1 abuse or neglect allegation. We chose to use all allegations, because previous studies have shown that substantiated and unsubstantiated reports result in equivalent developmental outcomes and indicate similar home distress. ${ }^{37-39}$

In addition, at age 12 years, self-report of lifetime (birth to 12 years) abuse was assessed through an Audio-Computer Assisted Self-Interview with 3 instruments developed for the LONGSCAN project. ${ }^{40}$ The Self Report of Physical Abuse and Assault assessed physical abuse, ranging from being kicked or punched to such offenses as being stabbed or shot by an adult. The Self Report of Sexual Abuse and Assault assessed increasingly severe sexual experiences, including nocontact experiences (eg, someone making you look at something sexual, such as a picture), fondling, oral-genital contact, and penetration. The Psychological Abuse Scale assessed experience with a range of caregiver behaviors that may be considered psychologically abusive, ranging from being called names "that made you feel really bad about yourself" to "a caregiver threatening to abandon you." Data were combined to yield a lifetime score (ie, occurred vs not occurred) for each of these 3 types of abuse.

\section{Data Analyses}

All data were analyzed with SPSS version 15.0 (Statistical Package for the Social Sciences, SPSS Inc, Chicago, Illinois). First we examined the bivariate relationship between lifetime maltreatment status and potential confounding variables (eg, sex and site of recruitment), unexplained gastrointestinal complaints, and psychological distress. Logistic regression was used to examine the relationship between each reported type of maltreatment and any gastrointestinal complaint while controlling for sex and site of recruitment. In addition, the mediating effect of psychological distress was tested according to the 4 steps outlined by Baron and Kenny. ${ }^{41}$ Step 1 is to examine whether maltreatment was associated with increased gastrointestinal symptoms, step 2 determines whether maltreatment is correlated with anxiety/depression, step 3 aims to show that anxiety/depression is related to gastrointestinal symptoms, and step 4 investigates whether the effect of maltreatment on gastrointestinal symptoms is suppressed when controlling for anxiety/depression. We ran the above analyses separately for CPS data and self-reported maltreatment.

To test whether maltreatment preceded or came after gastrointestinal symptoms, the age period ( 0 to 4 years, 4 to 6 years, 6 to 8 years, 8 to 12 years) at which a caregiver reported gastrointestinal symptoms of the child for the first time was compared with the age period when the first CPS maltreatment allegation occurred. A nonparametric sign test was performed to test the sign of the relationship between these 2 variables. ${ }^{42}$

\section{RESULTS}

\section{Comparison of Children Maltreated and Not Maltreated}

As can be seen from Table 1, maltreated youth were more likely to experience unexplained gastrointestinal symptoms and psychological distress. Significant differences by sex were found for type of maltreatment and gastrointestinal symptoms. Girls were less likely to be reported for physical abuse (30\% vs 36\% of boys, $P<.001)$, but more likely to be reported for sexual abuse $(20 \%$ vs $10 \%$ of boys, $P<.001)$. Girls selfreported more psychological maltreatment (44\% vs $37 \%$ of boys, $P<.05)$ and suffered more abdominal pain (30\% vs $15 \%$ of boys, $P<.001)$.

\section{Longitudinal Maltreatment Allegations Based on CPS Reports and Gastrointestinal Symptoms} Logistic regression analysis yielded significant associations between abdominal pain and CPS-recorded sexual abuse but not with the other types of maltreatment (Table 2). The proportion with abdominal pain in the group that was not maltreated was 520 of 1,000
Table 1. Demographics and Study-Related Variables in Children: Maltreated vs Not Maltreated and Abused vs Not Abused

\begin{tabular}{|c|c|c|c|c|c|c|}
\hline \multirow[b]{2}{*}{ Variable } & \multicolumn{3}{|c|}{ CPS-Reported Maltreatment } & \multicolumn{3}{|c|}{ Child Self-Reported Abuse } \\
\hline & $\begin{array}{l}\text { Maltreated } \\
(n=559)\end{array}$ & $\begin{array}{c}\text { Not } \\
\text { Maltreated } \\
(n=286)\end{array}$ & $\begin{array}{c}P \\
\text { Value }\end{array}$ & $\begin{array}{c}\text { Abused } \\
(n=402)\end{array}$ & $\begin{array}{c}\text { Not } \\
\text { Abused } \\
(n=425)\end{array}$ & $\begin{array}{c}P \\
\text { Value }\end{array}$ \\
\hline Sex, male, \% & 49.4 & 48.6 & NS & 45.8 & 51.3 & NS \\
\hline Race, \% & & & $<.001$ & & & NS \\
\hline White & 31.1 & 17.5 & & 27.1 & 25.2 & \\
\hline African American & 45.8 & 73.1 & & 54.2 & 56.7 & \\
\hline Other & 23.1 & 9.4 & & 18.7 & 18.1 & \\
\hline Age, years & 12 & 12 & NS & 12 & 12 & NS \\
\hline Nausea/vomiting, \% & 47.6 & 43.5 & NS & 53.4 & 38.0 & $<.001$ \\
\hline Abdominal pain, \% & 59.3 & 52.1 & .04 & 63.1 & 51.1 & $<.001$ \\
\hline $\begin{array}{l}\text { Psychological distress, } \\
\text { mean (SD) }\end{array}$ & $\begin{array}{c}4.8 \\
(4.7)\end{array}$ & $\begin{array}{c}3.7 \\
(3.7)\end{array}$ & $<.001$ & $\begin{array}{l}5.7 \\
(4.8)\end{array}$ & $\begin{array}{l}3.1 \\
(3.4)\end{array}$ & $<.001$ \\
\hline
\end{tabular}


compared with 672 of 1,000 for youth who experienced sexual abuse. Nausea/vomiting was not significantly associated with maltreatment. To determine the sensitivity of this analysis, we removed from the sample those who reported gastrointestinal symptoms before abuse. This step did not change the association between sexual abuse and abdominal pain (data not shown).

Taking advantage of the longitudinal nature of the data, we examined whether sexual abuse preceded unexplained gastrointestinal symptoms. Among those who were sexually abused, abdominal pain was reported before sexual abuse (8.8\%), at the same time $(46 \%)$, or at a later age $(45.2 \%)$ than abuse allegations. Sexual abuse preceded or coincided with abdominal pain significantly more often than after it $(z \cong 14.4 ; P<.001)$.

The results of the 4 -step mediation analyses were as follows: sexual abuse predicts abdominal pain (step 1 , as described above) and anxiety/depression $(\beta=0.08$, $t=2.2$; $P<.05$; step 2$)$. Anxiety/depression was associated with unexplained abdominal pain $(\mathrm{OR}=1.1 ; 95 \%$ CI, 1.1-1.2; step 3); and when it was included in the overall model, sexual abuse was no longer significantly related to abdominal pain complaints $(\mathrm{OR}=1.4 ; 95 \%$ CI, 0.9-2.2; step 4).

\section{Retrospective Self-Report of Abuse and Gastrointestinal Symptoms}

Because a large proportion of abuse is generally not reported to CPS, we reran the above analyses with selfreport of abuse at age 12 years. As shown in Table 3, self-reported recall of each type of abuse (psychological, physical, sexual) was significantly related to gastrointestinal symptoms. To test whether the effect of abuse is mediated by psychological distress, we again followed the 4 steps identified by Baron and Kenny. ${ }^{40}$ Abuse predicts abdominal pain and nausea/vomiting (step 1, Table 3). Psychological $(\beta=0.20, t=5.5$; $P<.001)$, physical $(\beta=0.12, t=3.5 ; P<.001)$, and sexual abuse $(\beta=0.15, t=4.4 ; P<.001)$ predicted anxiety/ depression (step 2). Anxiety/depression was associated with unexplained abdominal pain $(\mathrm{OR}=1.1 ; 95 \% \mathrm{CI}$, 1.1-1.2; step 3), and when it was included in the overall model, only physical abuse significantly predicted nausea/vomiting $(\mathrm{OR}=1.5 ; 95 \% \mathrm{CI}, 1.1-2.2$; step 4$)$.

\section{DISCUSSION}

This study observed an association between early childhood maltreatment and preadolescent gastrointestinal problems. Unexplained abdominal pain was associated with both prospectively collected CPS records and retrospective recall of lifetime sexual abuse. In addition, the data show that sexual abuse usually preceded or coincided with abdominal pain, suggesting that pain may be a consequence of childhood abuse. Self-reports of all types of abuse (sexual, psychological, and physical) were associated with increased abdominal pain and nausea/vomiting. This finding may mean that any type of abuse can possibly increase the risk of having unexplained gastrointestinal problems. The above-discussed associations were found independently of sex, which is similar to findings in the adult population, $^{43}$ and suggests that both boys and girls who are maltreated are at risk for developing unexplained gastrointestinal symptoms.

Psychological distress mediated the association between both CPS-recorded or self-reported abuse and gastrointestinal symptoms. This finding coincides with the literature showing increased psychological distress and dysregulation in the hypothalamic-pituitary-adrenal axis among those who are abused as a child. ${ }^{25,44,45}$ Psychological distress, however, only partially medi- 
ated the relation between physical abuse and nausea/vomiting, so other factors must play a role as well. Physical abuse may lead to abdominal injury, which has been associated with increased risk of unexplained gastrointestinal symptoms ${ }_{,}^{46,47}$ possibly through long-lasting changes in nociception. Ringel and colleagues observed increased pain to gut distention and associated changes in central pain processing in adult patients with unexplained abdominal pain who have been abused compared with those who have not. ${ }^{48}$

There can be many reasons why only sexual abuse, but no other types of CPS-recorded maltreatment, showed a relation with gastrointestinal symptoms. The most likely reason is that many children who have been maltreated are not reported to CPS. ${ }^{2}$ When CPS data are used to classify children as maltreated, many who have actually been maltreated will be misclassified, which would weaken the estimated association of maltreatment with gastrointestinal symptoms. There is evidence that sexual abuse may be a more potent contributor to poor health status than other types of abuse, explaining why this association remained significant, and that this outcome is possibly due to increased psychological distress in the sexually abused. ${ }^{25}$ The self-report data may be more accurate, although it can be plagued by recall bias. Youth may not remember being abused as an infant or toddler or may forget because they do not perceive it to have had a huge impact on their lives. Clearly, more studies are needed to address whether sexual abuse alone or all types of maltreatment are associated with increased complaints of unexplained symptoms.

This study has several limitations. First, data on gastrointestinal symptoms were collected by youth self-report and parent report and distilled from a larger questionnaire. We do not know the validity of these questions when used separately. The youth studied may have had an uninvestigated organic cause for their symptoms, although such a cause would be expected to be less than $5 \%$ to $10 \%$ of the sample. ${ }^{49}$ Second, even though this prospective study of child maltreatment is the longest and most comprehensive to date, the sample was selected to include many children at high-risk for maltreatment in early childhood; the results are not directly generalizable to the general population. Only 11 of 1,000 children have been sexually maltreated in the community ${ }^{2}$ compared with about $15 \%$ in our sample. In addition, rates of gastrointestinal symptoms were higher in our study, with about $46 \%$ complaining of nausea (vs $30 \%$ in community samples) and $56 \%$ of abdominal pain (vs $45 \%$ in the community). ${ }^{50}$ It is possible that children who were not abused in this sample were more likely than the general population to be living in adverse, stressful circumstances (eg, poverty, born to single parents, severe health issues). The contribution of other stressful factors, besides abuse, was not analyzed in the current study. Considering that abused children were compared with children who were not abused and who were dealing with many stressors in their lives, the association between gastrointestinal symptoms and abuse is probably reduced in this study. Community studies are needed to confirm these findings.

Even if the incidence of abuse and gastrointestinal symptoms are lower in primary care, finding that abuse recognition can modify the course of gastrointestinal symptoms would be important. To date only 1 case study described the positive effects of addressing abuse issues in the treatment of gastrointestinal symptoms ${ }^{51}$; thus, more studies are needed before we can draw any conclusions. Although diagnosis and treatment recommendations for children and youth who complain of abdominal pain and nausea can be found in recent reviews, ${ }^{52-54}$ treatment recommendations for abused patients with gastrointestinal symptoms are available for adults but not for youth. ${ }^{25,26}$

Unexplained gastrointestinal symptoms in at-risk youth may be psychosomatic and should prompt consideration of possible psychosocial contributors, particularly maltreatment. It may be essential for the safety of the youth and important for successful treatment to identify child maltreatment victims complaining of unexplained abdominal symptoms. More studies are needed to inform early medical interventions, especially studies focused on how unexplained gastrointestinal symptoms can develop as a consequence of childhood abuse and neglect.

To read or post commentaries in response to this article, see it online at http://www.annfammed.org/cgi/content/full/8/2/134.

Submitted November 24, 2008; submitted, revised, June 10, 2009; accepted July 10, 2009.

Authors' Affiliations: Center for Functional GI \& Motility Disorders, University of North Carolina, Chapel Hill, North Carolina (van Tilburg, Chitkara, Whitehead); Department of Social Medicine, University of North Carolina, Chapel Hill, North Carolina (Runyan); Department of Family Medicine, University of North Carolina, Chapel Hill, North Carolina (Zolotor); School of Social Work, University of Washington, Seattle, Washington (Graham); Department of Pediatrics, University of Maryland, Baltimore, Maryland (Dubowitz); Department of Psychology, San Diego State University, San Diego, California (Litrownik); Department of Pediatrics, Children's Memorial Hospital and Northwestern University Feinberg School of Medicine, Chicago, Illinois (Flaherty); Division of Pediatric Gastroenterology, Department of Pediatrics, University of North Carolina, Chapel Hill, North Carolina (Chitkara).

Author contributions: Dr Van Tilburg formulated the hypotheses, was responsible for all data analyses and interpretations, and took primary responsibility for writing the manuscript. Drs Runyan, Zolotor, Graham, Dubowitz, Litrownik, and Flaherty were responsible for 
obtaining funding, designing LONGSCAN, data collection, and critical revision of the manuscript. Drs Chitkara and Whitehead were involved in statistical analysis/interpretation of the data and critical revision of the manuscript.

Funding support: This research was supported by grants from the Children's Bureau, Office on Child Abuse and Neglect, Administration for Children, Youth, and Families (LONGSCAN grants 90CA1676, 90CA1677, 90CA1678, 90CA1679, 90CA1680, and 90(A1681). Dr van Tilburg was supported by a grant from the National Institute of Diabetes and Digestive and Kidney Diseases (R24 67674).

Acknowledgments: We would like to thank Shrikant Bangdiwala, PhD, research professor at the Department of Biostatistics at UNC-Chapel Hill, for statistical consultation on this project. Dr Bangdiwala directs the Biostatistics Unit in the Collaborative Studies Coordinating Center of LONGSCAN, as well as the Biometry Core for the UNC Center for Functional Gl and Motility Disorders, both located at the University of North Carolina at Chapel Hill.

\section{References}

1. Administration for Children and Families. Child Maltreatment 2006. Washington, DC: Administration for Children and Families; 2008.

2. Theodore AD, Chang JJ, Runyan DK, Hunter WM, Bangdiwala SI, Agans R. Epidemiologic features of the physical and sexual maltreatment of children in the Carolinas. Pediatrics. 2005;115(3): e331-e337.

3. Sedlak A, Broadhurst D. The Third National Incidence Study of Child Abuse and Neglect: NIS 3. Washington, DC: Administration for Children and Families, US Department of Health and Human Services; 1996.

4. Straus MA, Hamby SL, Finkelhor D, Moore DW, Runyan D. Identification of child maltreatment with the Parent-Child Conflict Tactics Scales: development and psychometric data for a national sample of American parents. Child Abuse Negl. 1998;22(4):249-270.

5. Gilbert R, Widom CS, Browne K, Fergusson D, Webb E, Janson S. Burden and consequences of child maltreatment in high-income countries. Lancet. 2009;373(9657):68-81.

6. Fergusson DM, Boden JM, Horwood LJ. Exposure to childhood sexual and physical abuse and adjustment in early adulthood. Child Abuse Negl. 2008;32(6):607-619

7. Widom CS. Posttraumatic stress disorder in abused and neglected children grown up. Am J Psychiatry. 1999;156(8):1223-1229.

8. Flaherty EG, Thompson R, Litrownik AJ, et al. Effect of early childhood adversity on child health. Arch Pediatr Adolesc Med. 2006;160(12):1232-1238.

9. Koloski NA, Talley NJ, Boyce PM. A history of abuse in community subjects with irritable bowel syndrome and functional dyspepsia: the role of other psychosocial variables. Digestion. 2005;72(2-3):86-96.

10. Hulme PA. Symptomatology and health care utilization of women primary care patients who experienced childhood sexual abuse. Child Abuse Negl. 2000;24(11):1471-1484

11. Walker EA, Gelfand A, Katon WJ, et al. Adult health status of women with histories of childhood abuse and neglect. Am J Med. 1999;107(4):332-339.

12. McCauley J, Kern DE, Kolodner K, et al. Clinical characteristics of women with a history of childhood abuse: unhealed wounds. JAMA 1997;277(17):1362-1368.

13. Golding JM, Cooper ML, George LK. Sexual assault history and health perceptions: seven general population studies. Health Psychol. 1997;16(5):417-425.
14. Talley NJ, Fett SL, Zinsmeister AR, Melton LJ III. Gastrointestinal tract symptoms and self-reported abuse: a population-based study. Gastroenterology. 1994;107(4):1040-1049.

15. Felitti VJ. Long-term medical consequences of incest, rape, and molestation. South Med J. 1991;84(3):328-331.

16. Leserman J, Drossman DA, Li ZM, Toomey TC, Nachman G, Glogau L. Sexual and physical abuse history in gastroenterology practice: How types of abuse impact health status. Psychosom Med. 1996;58(1):4-15.

17. Walker EA, Katon WJ, Roy-Byrne PP, Jemelka RP, Russo J. Histories of sexual victimization in patients with irritable bowel syndrome or inflammatory bowel disease. Am J Psychiatry. 1993;150(10): 1502-1506.

18. Drossman DA, Leserman J, Nachman G, et al. Sexual and physical abuse in women with functional or organic gastrointestinal disorders. Ann Intern Med. 1990;113(11):828-833.

19. Rimsza ME, Berg RA, Locke C. Sexual abuse: somatic and emotional reactions. Child Abuse Negl. 1988;12(2):201-208.

20. Biggs AM, Aziz Q, Tomenson B, Creed F. Effect of childhood adversity on health related quality of life in patients with upper abdominal or chest pain. Gut. 2004;53(2):180-186.

21. Biggs AM, Aziz Q, Tomenson B, Creed F. Do childhood adversity and recent social stress predict health care use in patients presenting with upper abdominal or chest pain? Psychosom Med. 2003;65(6):1020-1028

22. Fiddler M, Jackson J, Kapur N, Wells A, Creed F. Childhood adversity and frequent medical consultations. Gen Hosp Psychiatry. 2004;26(5):367-377.

23. Goodwin RD, Stein MB. Association between childhood trauma and physical disorders among adults in the United States. Psychol Med. 2004;34(3):509-520

24. Drossman DA. Sexual and physical abuse and gastrointestinal illness. Scand J Gastroenterol Suppl. 1995;208:90-96.

25. Leserman J. Sexual abuse history: prevalence, health effects, mediators, and psychological treatment. Psychosom Med. 2005;67(6): 906-915.

26. Drossman DA, Talley NJ, Leserman J, Olden KW, Barreiro MA. Sexual and Physical Abuse and Gastrointestinal Illness - Review and Recommendations. Ann Intern Med. 1995;123(10):782-794.

27. Talley NJ, Boyce PM, Jones $\mathrm{M}$. Is the association between irritable bowel syndrome and abuse explained by neuroticism? A population based study. Gut. 1998;42(1):47-53.

28. Salmon P, Skaife K, Rhodes J. Abuse, dissociation, and somatization in irritable bowel syndrome: towards an explanatory model. J Behav Med. 2003;26(1):1-18.

29. Saps M, Seshadri R, Sztainberg M, Schaffer G, Marshall BM, Di LC. A prospective school-based study of abdominal pain and other common somatic complaints in children. J Pediatr 2008 Epub. 25 November. IF: 4.017.

30. Zink T, Klesges L, Stevens S, Decker P. The development of a sexual abuse severity score: characteristics of childhood sexual abuse associated with trauma symptomatology, somatization, and alcohol abuse. J Interpers Violence. 2009;24(3):537-546.

31. Walker EA, Katon WJ, Hansom J, et al. Medical and psychiatric symptoms in women with childhood sexual abuse. Psychosom Med. 1992;54(6):658-664.

32. Whitehead WE, Palsson O, Jones KR. Systematic review of the comorbidity of irritable bowel syndrome with other disorders: what are the causes and implications? Gastroenterology. 2002;122(4): $1140-1156$.

33. Achenbach TM, Edelbrock C. Manual for the Child Behavior Checklist/4-18 and 1991 Profile. Burlington, VT: University of Vermont, Department of Psychiatry; 1991. http://www.aseba.org/. 
34. Schurman JV, Friesen CA, Danda CE, et al. Diagnosing functional abdominal pain with the Rome II criteria: parent, child, and clinician agreement. J Pediatr Gastroenterol Nutr. 2005;41(3):291-295.

35. Caplan A, Walker L, Rasquin A. Validation of the pediatric Rome II criteria for functional gastrointestinal disorders using the questionnaire on pediatric gastrointestinal symptoms. J Pediatr Gastroenterol Nutr. 2005;41(3):305-316.

36. Barnett D, Manley JT, Cicchetti D. Defining child maltreatment: The interface between policy and research. In: Cicchetti DTSL, ed. Child Abuse, Child Development, and Social Policy. Norwood, NJ: Ablex; 1993:7-74.

37. Hussey JM, Marshall JM, English DJ, et al. Defining maltreatment according to substantiation: distinction without a difference? Child Abuse Negl. 2005;29(5):479-492.

38. Leiter J, Myers KA, Zingraff MT. Substantiated and unsubstantiated cases of child maltreatment: Do their consequences differ? Soc Work Res. 1994;18(2):67-82.

39. Drake B. Unraveling "unsubstantiated". Child Maltreat. 1996;1(3):261-271.

40. Eerson MD, Smith JB, Hussey JM, et al. Concordance between adolescent reports of childhood abuse and Child Protective Service determinations in an at-risk sample of young adolescents. Child Maltreat. 2008;3(1):14-26.

41. Baron RM, Kenny DA. The moderator-mediator variable distinction in social psychological research: conceptual, strategic, and statistical considerations. J Pers Soc Psychol. 1986;51(6):1173-1182.

42. Conover WJ. Practical Nonparametric Statistics. 3rd ed. New York, NY: Wiley; 1999.

43. Leserman J, Drossman DA. Relationship of abuse history to functional gastrointestinal disorders and symptoms: some possible mediating mechanisms. Trauma Violence Abuse. 2007;8(3):331-343.

44. Van Voorhees E, Scarpa A. The effects of child maltreatment on the hypothalamic-pituitary-adrenal axis. Trauma Violence Abuse. 2004;5(4):333-352
45. Shea A, Walsh C, Macmillan H, Steiner M. Child maltreatment and HPA axis dysregulation: relationship to major depressive disorder and post traumatic stress disorder in females. Psychoneuroendocrinology. 2005;30(2):162-178.

46. Smith C, Nordstrom E, Sengupta JN, Miranda A. Neonatal gastric suctioning results in chronic visceral and somatic hyperalgesia: Role of corticotropin releasing factor. Neurogastroenterol Motil. 2004;19(8):692-699.

47. Anand KJ, Runeson B, Jacobson B. Gastric suction at birth associated with long-term risk for functional intestinal disorders in later life. J Pediatr. 2004;144(4):449-454.

48. Ringel $Y$, Drossman DA, Leserman JL, et al. Effect of abuse history on pain reports and brain responses to aversive visceral stimulation: an FMRI study. Gastroenterology. 2008;134(2):396-404

49. Apley J, Naish N. Recurrent abdominal pains: a field survey of 1,000 school children. Arch Dis Child. 1958;33(168):165-170.

50. Saps M, Sztainberg M, Di LC. A prospective community-based study of gastroenterological symptoms in school-age children. J Pediatr Gastroenterol Nutr. 2006;43(4):477-482

51. Drossman DA, Ringel $Y$, Vogt $B A$, et al. Alterations of brain activity associated with resolution of emotional distress and pain in a case of severe irritable bowel syndrome. Gastroenterology. 2003;124(3):754-761

52. Di Lorenzo C, Colletti RB, Lehmann HP, et al. Chronic abdominal pain in children: a clinical report of the American Academy of Pediatrics and the North American Society for Pediatric Gastroenterology, Hepatology and Nutrition. J Pediatr Gastroenterol Nutr. 2005;40(3):245-248.

53. Di Lorenzo C, Colletti RB, Lehmann HP, et al. Chronic abdominal pain In children: a technical report of the American Academy of Pediatrics and the North American Society for Pediatric Gastroenterology, Hepatology and Nutrition. J Pediatr Gastroenterol Nutr. 2005;40(3):249-261.

54. Rome III. The Functional Gastrointestinal Disorders. 3rd ed. Degnon Associates; 2006 